\title{
Effect of levamisole on gastrointestinal nematodes and weight gain of grazing livestock in the municipality of San Jose Chiltepec, Oaxaca, Mexico
}

Ulises Libreros-Osorio

Universidad Realistica de Mexico

Daniela Donaji Vázquez-Arrieta

Universidad Realistica de Mexico

Ilhuicamina Daniel Limón

Benemerita Universidad Autonoma de Puebla

Aleidy Patricio-Martínez

Benemerita Universidad Autonoma de Puebla

Felipe Patricio-Martínez ( $\nabla$ felipe.patmar@gmail.com )

Universidad Realística de México https://orcid.org/0000-0003-0531-7229

Research Article

Keywords: levamisole, ivermectin, anthelmintic, weight gain, grazing livestock

Posted Date: November 10th, 2021

DOI: https://doi.org/10.21203/rs.3.rs-897445/v1

License: (c) (i) This work is licensed under a Creative Commons Attribution 4.0 International License. Read Full License 


\section{Abstract}

The aim of the present work was to study the effect of administration of levamisole on parasitic load of gastrointestinal nematodes (GIN) and the percentage of weight gain of grazing cattle. The animals were randomly distributed to form three experimental groups, levamisole, ivermectin and control. The collection of feces samples was carried out one day before and 15 days' post-treatment and subsequently it was quantifying the eggs number per gram of feces. The body weight of the animals was recorded at days $0,15,30$ and 45 after treatments to evaluate its gain. The results observed up to the final day (45 days' post-treatment) showed the group treated with Ivermectin had a $10.1 \%$ increase in body weight, while the group under Levamisole treatment had an increase of $14.3 \%$. The groups under ivermectin and levamisole showed a decrease in the number of eggs per grams of feces (EPG), which were measured 15 days after their treatment (22.5 EPG in ivermectin) and (55.0 EPG in levamisole) compared to the vehicle group (377.5 EPG) and pre-treatment (486.5 EPG). In the present work, it was possible to show that with two subcutaneous administrations of levamisole in grazing calves in the municipality of Chiltepec, Oaxaca, it's possible to increase the weight in cattle while decreasing its parasite load of GIN. However, it is necessary to determine the anthelmintic resistance in farms that report the use of levamisole with different treatment and repeated doses of levamisole.

\section{Introduction}

Gastrointestinal nematode (GIN) infections gravely affect animal health (Waller 2003), and productivity (Charlier et al. 2009), farm profitability (Morgan et al. 2013) and overall welfare in growing cattle all over the world (Vande Velde et al. 2018). In Mexico, particularly, it has been demonstrated that parasitic diseases in livestock can cause serious economic loss. In fact, the yearly economic loss due to the six major parasites of cattle in Mexico was estimated to be US\$ 1.41 billion (Rodríguez-Vivas et al. 2017).

The main effect of GIN infections in grazing beef cattle production is a reduction in weight gain (Mertz et al. 2005) so that, pharmacological control of GIN in grazing cattle could be necessary (Vande Velde et al. 2018). Up until now, GIN infection control in livestock cattle has been performed by administering drugs such as macrocyclic lactones, benzimidazoles and imidazothiazoles (McArthur and Reinemeyer 2014; Gasbarre 2014). However, the increase of resistant nematodes to anthelmintic macrocyclic lactones in the warm subhumid tropics of Mexico has presented a challenge (Canul-Ku et al. 2012).

The levamisole an imidazothiazole derivative drug have an anthelmintic efficacy and low resistance to GIN (Williams and Broussard 1995; Suarez and Cristel 2007; Cristel et al. 2017; Ali et al. 2018; Pivoto et al. 2020). Similarly, levamisole (alone or combined) has been shown to increase weight gain and economic profit (Williams 1991; Candy et al. 2018; Pivoto et al. 2020). Therefore, the aim of this work was evaluate the anthelmintic effect with a single treatment of levamisole as well as its impact on weight gain in grazing cattle within the municipality of Chiltepec, Oaxaca, Mexico.

Matarial And Manthnde

Loading [MathJax]/jax/output/CommonHTML/fonts/TeX/fontdata.js

Page 2/13 


\section{Localization}

This study was carried out in the town of San Jose Chiltepec, Oaxaca, Mexico. This municipality is located at 30 meters above sea level and has a warm-humid climate with rains all year round ( $50.8 \%)$, as well as warm-humid with abundant rains in summer (49.5\%). The range of rainfall is $2000-4000 \mathrm{~mm}$.

\section{Animals and experimental design}

Sixty calves (male and female) of the Beefmaster breed within the age range of ten to twelve months were used for this study. The animals were extensively grazed with palisade grass (Brachiaria brizantha) and stargrass (Cynodon nlemfuensis). No animal had any anthelmintic treatment before the collection of samples for the coprology test, even with counts of 450 eggs per gram of feces (epg) were obtained.

From November 26, 2019 to January 10, 2020, the experiment was carried out with the 60 calves, from which fecal samples were collected to measure the parasite load. This process was done a day before and 15 days after the administration of drugs. In the temporal line (Fig. 1), it was assigned day zero due to the formation of three experimental groups for the administration of Levamisole $(n=20)$, ivermectin ( $n$ $=20)$ or vehicle $(n=20)$. The drugs were administered on day zero and day 15 for the second doses of Levamisole $5 \mathrm{mg} / \mathrm{kg}$ (i.m.), and Ivermectin $0.2 \mathrm{mg} / \mathrm{kg}$ (s.c.). Ivermectin was used as a positive control and thus we have a comparative group. Individual coprology samples were carried out on days -1 and 15 , and the body weight record was made on days $0,15,30$ and 45 .

\section{Parasitological analysis}

Fecal samples were collected and transported in a cooler at approximately $4^{\circ} \mathrm{C}$ to be examined by the modified McMaster technique (Roberts and O'Sullivan 1949), where 1 egg represents $10 \mathrm{epg}$. Fecal egg count reduction (FECR) was calculated as follows:

$$
F E C R=\frac{[(\text { AvgFECPre }- \text { treatment })-(\text { AvgFECPost }- \text { treatment })]}{(\text { AvgFECPre }- \text { treatment })} * 100
$$

where Avg is average.

The standard of $<90 \%$ reduction (McKenna 1994; Levecke et al. 2012) post-treatment was used to define the effectiveness of a drug as anthelmintic. Since the objective of the study was to measure the effect of Levamisole on body weight gain, resistance to anthelmintic was not defined.

\section{Statistical Analyses}

All the results were expressed as mean \pm standard error of the mean (SEM). Body weight control expressed in the table were subject to one-way ANOVA test, followed by a Tuckey post hoc analysis. On the other hand, the percentage body weight gains to the 45 days' post-treatment and the number of eggs 
per gram of feces 15 days' post-treatment were done by the Kruskal-Wallis test, followed by a Dunns post hoc analysis. The criterion for significance was $p<0.05$.

\section{Results}

Body weight was recorded (Table 1) and subsequently studied the percentage of body weight gain in all experimental groups (Fig. 2) on days $0,15,30$ and 45 . The ivermectin and levamisole groups showed increases in the body weight with significant differences $(p<0.01$ and $p<0.001)$ at 30 days' posttreatment ( $246.4 \pm 2.3$ and $248.9 \pm 3.5$, respectively) and 45 days' post-treatment $(253.5 \pm 2.3$ and $260.1 \pm$ 3.5 , respectively) compared with day $0(230.2 \pm 2.3$ and $227.7 \pm 3.6$, respectively). The vehicle group only had a significant difference at 45 days' post-treatment compared to the pre-treatment (Table 1). The comparison in the body weight gain of the calves treated with ivermectin, increased the registered weight against that of the vehicle group showed a statistically significant difference at days 15, 30 and 45 (7.3 \pm $0.94,8.9 \pm 0.22$ and $8.9 \pm 0.22$, respectively). On the other hand, the weight increase within the levamisole group against that of the vehicle group and the ivermectin group showed a statistical difference, at 15, 30 and 45 days $(9.9 \pm 0.49,11.2 \pm 0.20$ and $11.2 \pm 0.6$, respectively). Likewise, the percentage of weight gain observed up to day 45 showed an increase of $10.1 \%$ in the ivermectin group compared to the vehicle group $(p<0.001)$, which had an increase of $7.0 \%$. However, the levamisole group showed an increase of $14.3 \%$ compared to both the ivermectin $(p<0.001)$ and vehicle groups $(p<0.01)$ (Fig. 2$)$.

Table 1

Body weight control in the experimental groups. The increase in weight in cattle is observed during pretreatment and post-treatment. Values expressed in kilograms $(\mathrm{kg})$

\begin{tabular}{|c|c|c|c|c|}
\hline \multirow[t]{2}{*}{ Experimental Group } & \multirow{2}{*}{$\begin{array}{l}\text { Pre-treatment } \\
\text { O D }\end{array}$} & \multicolumn{3}{|c|}{ Post-treatment } \\
\hline & & $15 \mathrm{D}$ & $30 \mathrm{D}$ & $45 \mathrm{D}$ \\
\hline Vehicle & $245.1 \pm 1.4$ & $250.4 \pm 1.4$ & $256.5 \pm 1.4$ & $262.3 \pm 1.5^{\star \star \star}$ \\
\hline Ivermectin & $230.2 \pm 2.3$ & $237.5 \pm 2.4$ & $246.4 \pm 2.3^{\star \star}$ & $253.5 \pm 2.3^{\star \star \star,++}$ \\
\hline Levamisole & $227.7 \pm 3.6$ & $237.6 \pm 3.5$ & $248.9 \pm 3.5^{\star \star \star}$ & $260.1 \pm 3.5^{\star \star \star},++$ \\
\hline
\end{tabular}

To determine the decrease in the parasite load, the number of eggs per gram of feces (EPG) was measured 15 days after treatment. The ivermectin and levamisole groups showed a decrease in EPG (22.5 EPG and 55.0 EPG, respectively) compared to the vehicle group (377.5 EPG) $p<0.001$, and all animals before treatment (without an assigned group) (486.5 EPG) with statistical difference $(p<0.001)$ (Fig. 3). On the other hand, the results of fecal egg count reduction (FECR) showed a value $>90 \%$ in the ivermectin group (95.4\%). However, the vehicle and levamisole group had a value $<90 \%(24.3 \%$ and $84.1 \%$, respectively) (Table 2 ). 
Table 2

Fecal egg count reduction (FECR) after of treatment with Ivermectin or levaminsole in bovines.

\begin{tabular}{|llll|}
\hline Experimental Group & Day & Mean \pm SEM & Reduction \% vs day 0 \\
\hline Vehicle & 0 & $499.2 \pm 93.0$ & 24.3 \\
\cline { 1 - 3 } Ivermectine & 15 & $377.5 \pm 51.5$ & \\
\cline { 1 - 2 } & 0 & $499.2 \pm 93.0$ & 95.4 \\
Levamisole & 15 & $22.5 \pm 7.6$ & \\
& 0 & $499.2 \pm 93.0$ & 84.1 \\
& 15 & $55.0 \pm 30.9$ & \\
\hline
\end{tabular}

\section{Discussion}

In the present work we study the effect of levamisole as an anthelmintic and its effect on the weight gain of grazing cattle in the municipality of Chiltepec, Oaxaca, Mexico. The efficacy of levamisole on bovine parasitosis has been demonstrated for several decades (Ciordia and McCampbell 1971; Pouplard et al. 1986; Vanparijs and Quick 1991), particularly against gastrointestinal nematodes (GIN) (Williams 1991; Anziani et al. 2004; de Soutello et al. 2010; Idika et al. 2012). However, in this study we show that levamisole maintains the anthelmintic effect and increases weight gain in grazing cattle with two administrations in a period of 15 days, with an effect that last until day 45 (Fig. 2; Table 2) in the Chiltepec region, Oaxaca. To determine that levamisole has such efficacy, we used ivermectin as a control that has also shown to have anthelmintic resistance in cattle from Mexico (Muñiz-Lagunes et al. 2015; Alonso-Díaz et al. 2015; Alegría-López et al. 2015). We observed that levamisole is more effective than ivermectin in increasing both the gain and the percentage of weight of the animals. It is likely that parasitic control with levamisole from an early age in calves can interfere both in animal welfare, as well as in the stimulation of innate immunity (Pekmezci and Cakiroglu 2009). Reports have shown that levamisole can enhance the immunology responses and therefore improve the performance of production animals (Mohri et al. 2005). However, it has not been shown whether levamisole treatment can have a direct correlation between weight gain and its immunomodulatory effects in both rearing and adulthood in beef producing cattle.

On the other hand, a great impact of resistance to anthelmintic has been manifested in cattle both in our country and around the world (Canul-Ku et al. 2012; Muñiz-Lagunes et al. 2015; Pivoto et al. 2020). In fact, the main factors for the development of resistance to anthelmintic drugs is underdosing, frequent treatments and low sheltering. That is why it is necessary to regulate the use of anthelmintic only with prescription in cattle, as is the case of Denmark, where since 2000 it is required to register all production animal prescriptions at the "VetSat", the danish system monitoring the use of veterinary drugs (Stege et al. 2003). The standard for the determination of anthelmintic resistance in cattle is carried out by the 
Fecal Egg Count Reduction Test (FECR) (Levecke et al. 2012). Resistance is inferred when there is a $<95 \%$ reduction in FECR, 7-10 days after treatment (Waghorn et al. 2006; Levecke et al. 2012). In the present work, it was inferred 15 days after treatment, and a decrease of $95.4 \%$ and $84.1 \%$ are shown in FECR for ivermectin and levamisole, respectively. Although our objective did not contemplate evaluating anthelmintic resistance, it highlights the need to follow up the use of levamisole for a longer time and with the study of fecal samples in a longer time.

In conclusion, the present work demonstrated that two subcutaneous administrations of levamisole in grazing calves in the municipality of Chiltepec, Oaxaca, are able to increase the body weight gain of animals, as well as decrease their parasite load of GIN. However, it is necessary to determine the anthelmintic resistance in farms that report the use of levamisole with different treatment and repeated doses of levamisole.

\section{Declarations}

\section{Acknowledgements}

Thanks to Dina Andrea Macias (Ba in Communications) for editing the English language text.

Thanks to Unión Ganadera Regional del Norte de Oaxaca for the processing of samples made in this work.

\section{Authors' contributions}

The conceived, designed the experiment and data collection was performed by Libreros-Osorio U., and Patricio F. Data analyses were performed by Vázquez-Arrieta DD. The manuscript preparation was performed by Limon ID., Patricio-Martínez A., and Patricio F. All of the authors read and approved the final manuscript.

\section{Funding}

This study was supported by Livestock Pharmacy "Santa Inés" from Tuxtepec, Oaxaca, México and the support of Universidad Realística de México (URM).

\section{Ethics approval}

The experimental procedures with grazing livestock followed all applicable international and national guidelines for the care and use of animals.

\section{Consent to participate}

Not applicable. 
Not applicable.

\section{Availability of data and material}

The data that support the findings of the present study are available with the corresponding author upon reasonable request.

\section{Code availability}

Not applicable.

\section{Conflict of interest}

The authors declare no conflict of interest with any aspect concerning the writing and publication of this article.

\section{References}

Alegría-López, M. A., Rodríguez-Vivas, R. I., Torres-Acosta, J. F., Ojeda-Chi, M. M., and Rosado-Aguilar, J. A. 2015. Use of Ivermectin as Endoparasiticide in Tropical Cattle Herds Generates Resistance in Gastrointestinal Nematodes and the Tick Rhipicephalus microplus (Acari: Ixodidae). Journal of medical entomology, 52(2), 214-221. https://doi.org/10.1093/jme/tju025

Ali, M. S., Saeed, K., Rashid, I., ljaz, M., Akbar, H., Rashid, M., and Ashraf, K. 2018. Anthelmintic Drugs: Their Efficacy and Cost-Effectiveness in Different Parity Cattle. The Journal of parasitology, 104(1), 7985. https://doi.org/10.1645/17-4

Alonso-Díaz, M. A., Arnaud-Ochoa, R. A., Becerra-Nava, R., Torres-Acosta, J. F., Rodriguez-Vivas, R. I., and Quiroz-Romero, R. H. 2015. Frequency of cattle farms with ivermectin resistant gastrointestinal nematodes in Veracruz, Mexico. Veterinary parasitology, 212(3-4), 439443. https://doi.org/10.1016/j.vetpar.2015.07.023

Anziani, O. S., Suarez, V., Guglielmone, A. A., Warnke, O., Grande, H., and Coles, G. C. 2004. Resistance to benzimidazole and macrocyclic lactone anthelmintics in cattle nematodes in Argentina. Veterinary parasitology, 122(4), 303-306. https://doi.org/10.1016/j.vetpar.2004.05.018

Candy, P. M., Waghorn, T. S., Miller, C. M., Ganesh, S., and Leathwick, D. M. 2018. The effect on liveweight gain of using anthelmintics with incomplete efficacy against resistant Cooperia oncophora in cattle. Veterinary parasitology, 251, 56-62. https://doi.org/10.1016/j.vetpar.2017.12.023

Canul-Ku, H. L., Rodríguez-Vivas, R. I., Torres-Acosta, J. F., Aguilar-Caballero, A. J., Pérez-Cogollo, L. C., and Ojeda-Chi, M. M. 2012. Prevalence of cattle herds with ivermectin resistant nematodes in the hot subhumid tropics of Mexico. Veterinary parasitology, 183(3-4), 292- 
Charlier, J., Höglund, J., von Samson-Himmelstjerna, G., Dorny, P., and Vercruysse, J. 2009.

Gastrointestinal nematode infections in adult dairy cattle: impact on production, diagnosis and control. Veterinary parasitology, 164(1), 70-79. https://doi.org/10.1016/j.vetpar.2009.04.012

Ciordia, H., and McCampbell, H. C. 1971. Activity of levamisole (I form of tetramisole) in control of nematode parasites and body weight gains of feedlot cattle. American journal of veterinary research, 32(4), 545-550.

Cristel, S., Fiel, C., Anziani, O., Descarga, C., Cetrá, B., Romero, J., Fernández, S., Entrocasso, C., Lloberas, M., Medus, D., and Steffan, P. 2017. Anthelmintic resistance in grazing beef cattle in central and northeastern areas of Argentina - An update. Veterinary parasitology, regional studies and reports, 9, 2528. https://doi.org/10.1016/j.vprsr.2017.04.003

de Soutello, R. V., Coelho, W. M., de Oliveira, F. P., Fonzar, J. F., Luquetti, B. C., de Souza, R. F., Seno, M. C., and do Amarante, A. F. 2010. Evaluation of reduction in egg shedding of gastrointestinal nematodes in cattle following administration of anthelmintics. Revista brasileira de parasitologia veterinaria = Brazilian journal of veterinary parasitology: Orgao Oficial do Colegio Brasileiro de Parasitologia Veterinaria, 19(3), 183-185. https://doi.org/10.1590/s1984-29612010000300011

Gasbarre L. C. 2014. Anthelmintic resistance in cattle nematodes in the US. Veterinary parasitology, 204(1-2), 3-11. https://doi.org/10.1016/j.vetpar.2014.03.017

Idika, I. K., Okonkwo, E. A., Onah, D. N., Ezeh, I. O., Iheagwam, C. N., and Nwosu, C. O. 2012. Efficacy of levamisole and ivermectin in the control of bovine parasitic gastroenteritis in the sub-humid savanna zone of southeastern Nigeria. Parasitology research, 111(4), 16831687. https://doi.org/10.1007/s00436-012-3007-6

Levecke, B., Dobson, R. J., Speybroeck, N., Vercruysse, J., and Charlier, J. 2012. Novel insights in the faecal egg count reduction test for monitoring drug efficacy against gastrointestinal nematodes of veterinary importance. Veterinary parasitology, 188(3-4), 391396. https://doi.org/10.1016/j.vetpar.2012.03.020

McArthur, M. J., and Reinemeyer, C. R. 2014. Herding the U.S. cattle industry toward a paradigm shift in parasite control. Veterinary parasitology, 204(1-2), 34-43. https://doi.org/10.1016/j.vetpar.2013.12.021

McKenna P. B. 1994. Criteria for diagnosing anthelmintic resistance by the faecal egg count reduction test. New Zealand veterinary journal, 42(4), 153-154. https://doi.org/10.1080/00480169.1994.35808

Mertz, K. J., Hildreth, M. B., and Epperson, W. B. 2005. Assessment of the effect of gastrointestinal nematode infestation on weight gain in grazing beef cattle. Journal of the American Veterinary Medical Association, 226(5), 779-783. https://doi.org/10.2460/javma.2005.226.779 
Mohri, M., Seifi, H.A., and Zamani Sani, S.H. 2005. Effects of oral administration of levamisole on nonspecific immunity, serum proteins and health in normal colostrum-fed neonatal dairy calves. Comparative Clinical Pathology 13, 132-136. https://doi.org/10.1007/s00580-004-0528-0

Morgan, E.R., Charlier, J., Hendrickx, G., Biggeri, A., Catalan, D., Von Samson-Himmelstjerna, G., Demeler, J., Müller, E., Van Dijk, J., Kenyon, F., Skuce, P., Höglund, J., O'Kiely, P., Van Ranst, B., De Waal, T., Rinaldi, L., Cringoli, G., Hertzberg, H., Torgerson, P., Wolstenholme, A., and Vercruysse, J. 2013. Global Change and Helminth Infections in Grazing Ruminants in Europe: Impacts, Trends and Sustainable Solutions. Agriculture 3(3), 484-502. https://doi.org/10.3390/agriculture3030484

Muñiz-Lagunes, A., González-Garduño, R., López-Arellano, M. E., Ramírez-Valverde, R., Ruíz-Flores, A., García-Muñiz, G., Ramírez-Vargas, G., Mendoza-de Gives, P., and Torres-Hernández, G. 2015. Anthelmintic resistance in gastrointestinal nematodes from grazing beef cattle in Campeche State, Mexico. Tropical animal health and production, 47(6), 1049-1054. https://doi.org/10.1007/s11250-015-0826-3

Pekmezci, D., and Cakiroglu, D. 2009. Investigation of immunmodulatory effects of levamisole and vitamin $\mathrm{E}$ on Immunity and some blood parameters in newborn Jersey calves. Veterinary research communications, 33(7), 711-721. https://doi.org/10.1007/s11259-009-9220-9

Pivoto, F. L., Cezar, A. S., Vogel, F., Marques, C. B., Alves, M., Becker, C. C., and do Rego Leal, M. L. 2020. Economic losses caused by the use of low-efficacy anthelmintic drugs in growing heifers. Tropical animal health and production, 52(3), 1365-1374. https://doi.org/10.1007/s11250-019-02144-1

Pouplard, L., Lekeux, P., and Detry, M. 1986. Efficacy of ivermectin and levamisole against immature Dictyocaulus viviparus in cattle. The Veterinary record, 118(20), 557559. https://doi.org/10.1136/vr.118.20.557

Roberts, F., and O'Sullivan, P. 1949. Methods for egg counts and larval cultures for strongyles infecting the gastrointestinal tract of cattle. Australian Journal of Agricultural Research, 1,99103. https://doi.org/10.1071/AR9500099

Rodríguez-Vivas, R. I., Grisi, L., Pérez de León, A. A., Villela, H. S., Torres-Acosta, J. F. J., Fragoso Sánchez, H., Romero Salas, D., Rosario Cruz, R., Saldierna, F., and García Carrasco, D. 2017. Potential economic impact assessment for cattle parasites in Mexico. Review. Revista Mexicana de Ciencias Pecuarias, 8(1),61-74. https://doi.org/10.22319/rmcp.v8i1.4305

Stege, H., Bager, F., Jacobsen, E., and Thougaard, A. 2003. VETSTAT-the Danish system for surveillance of the veterinary use of drugs for production animals. Preventive veterinary medicine, 57(3), 105115. https://doi.org/10.1016/s0167-5877(02)00233-7

Suarez, V. H., and Cristel, S. L. 2007. Anthelmintic resistance in cattle nematode in the western Pampeana Region of Argentina. Veterinary parasitology, 144(1-2), 111- 
Vande Velde, F., Charlier, J., and Claerebout, E. 2018. Farmer Behavior and Gastrointestinal Nematodes in Ruminant Livestock-Uptake of Sustainable Control Approaches. Frontiers in veterinary science, 5, 255. https://doi.org/10.3389/fvets.2018.00255

Vanparijs, O., and Quick, J. M. 1991. Efficacy of levamisole pour-on compared with levamisole subcutaneous injection against Dictyocaulus viviparus infection in calves. Veterinary parasitology, 38(1), 75-79. https://doi.org/10.1016/0304-4017(91)90011-j

Waghorn, T. S., Leathwick, D. M., Rhodes, A. P., Jackson, R., Pomroy, W. E., West, D. M., and Moffat, J. R. 2006. Prevalence of anthelmintic resistance on 62 beef cattle farms in the North Island of New Zealand. New Zealand veterinary journal, 54(6), 278-282. https://doi.org/10.1080/00480169.2006.36711

Waller P. J. 2003. Global perspectives on nematode parasite control in ruminant livestock: the need to adopt alternatives to chemotherapy, with emphasis on biological control. Animal health research reviews, 4(1), 35-43. https://doi.org/10.1079/ahrr200350

Williams J. C. 1991. Efficacy of albendazole, levamisole and fenbendazole against gastrointestinal nematodes of cattle, with emphasis on inhibited early fourth stage Ostertagia ostertagi larvae. Veterinary parasitology, 40(1-2), 59-71. https://doi.org/10.1016/0304-4017(91)90083-8

Williams, J. C., and Broussard, S. D. 1995. Comparative efficacy of levamisole, thiabendazole and fenbendazole against cattle gastrointestinal nematodes. Veterinary parasitology, 58(1-2), 8390. https://doi.org/10.1016/0304-4017(94)00701-d

\section{Figures}




\section{EXPERIMENTAL DESIGN}

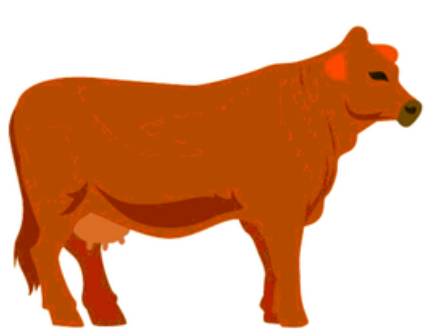

Beefmaster

calves

(220-240 kg)

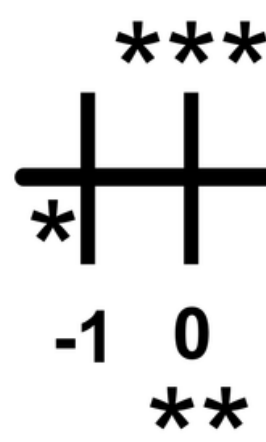

collection fecal

samples

*
Body weight

record

** administration

of anthelmintic drugs $* * *$

Figure 1

Experimental design. Three groups were obtained: Vehicle, Ivermectin and Levamisole. The administration of anthelmintic drugs was on day zero and day 15 . The sampling feces was performed one day before deworming and on day 30 post-deworming. On the other hand, the weight of the animals was taken every 15 days for the determination of the weight gain of the animals. 


\section{$45 \mathrm{D}$ \\ post-treatment}

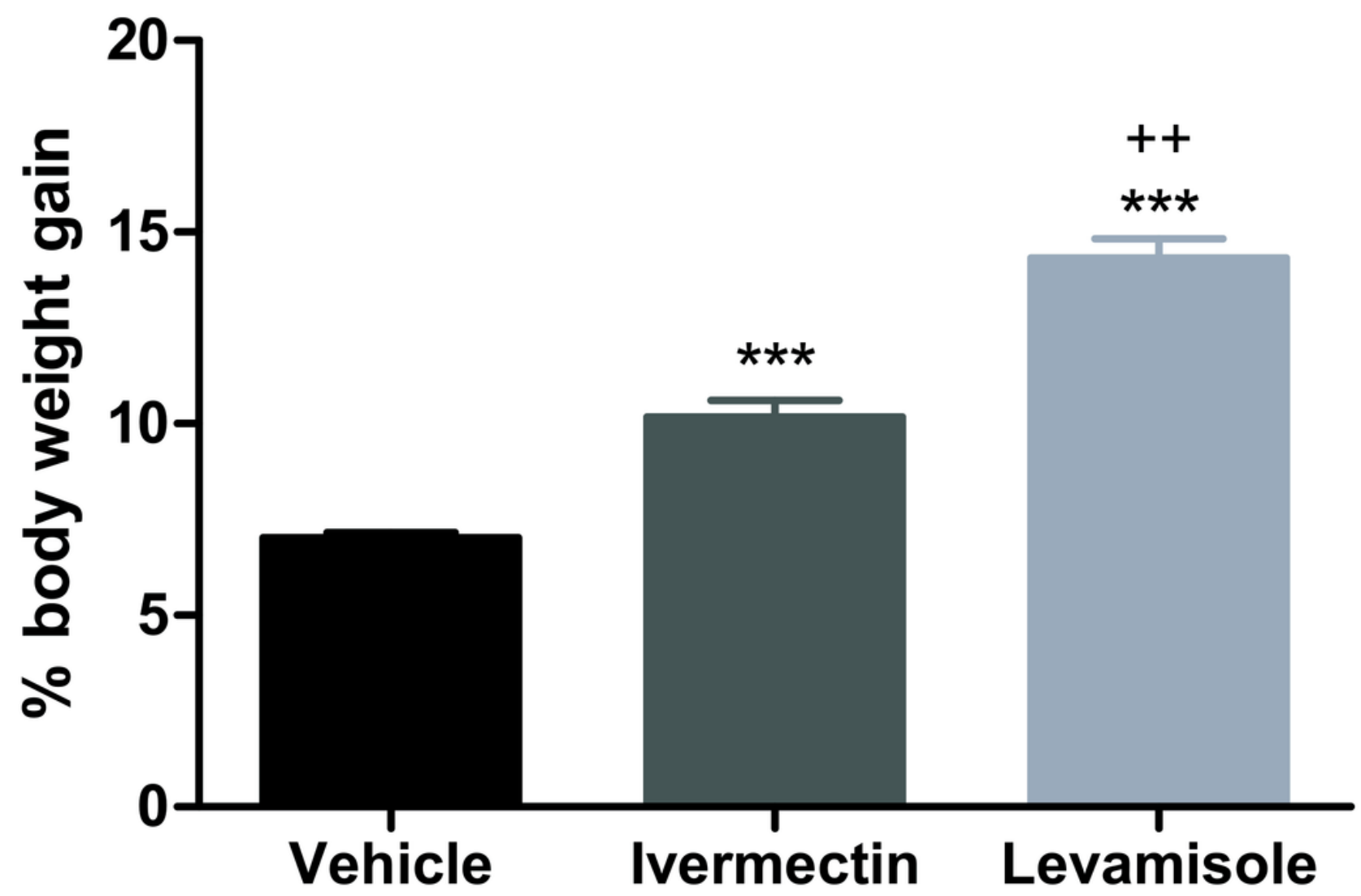

Figure 2

The two doses administration of levamisole increase the percentage body weight gain to the 45 days' post-treatment. It is show the effective result of levamisole regarding to ivermectin. The values show mean \pm SEM, with a Kruskal-Wallis test, followed a Dunns post hoc analysis: ${ }^{\star \star \star} p<0.001$ vs vehicle group; $++p<0.01$ vs ivermectin group. ( $n=20$ bovines per group). 

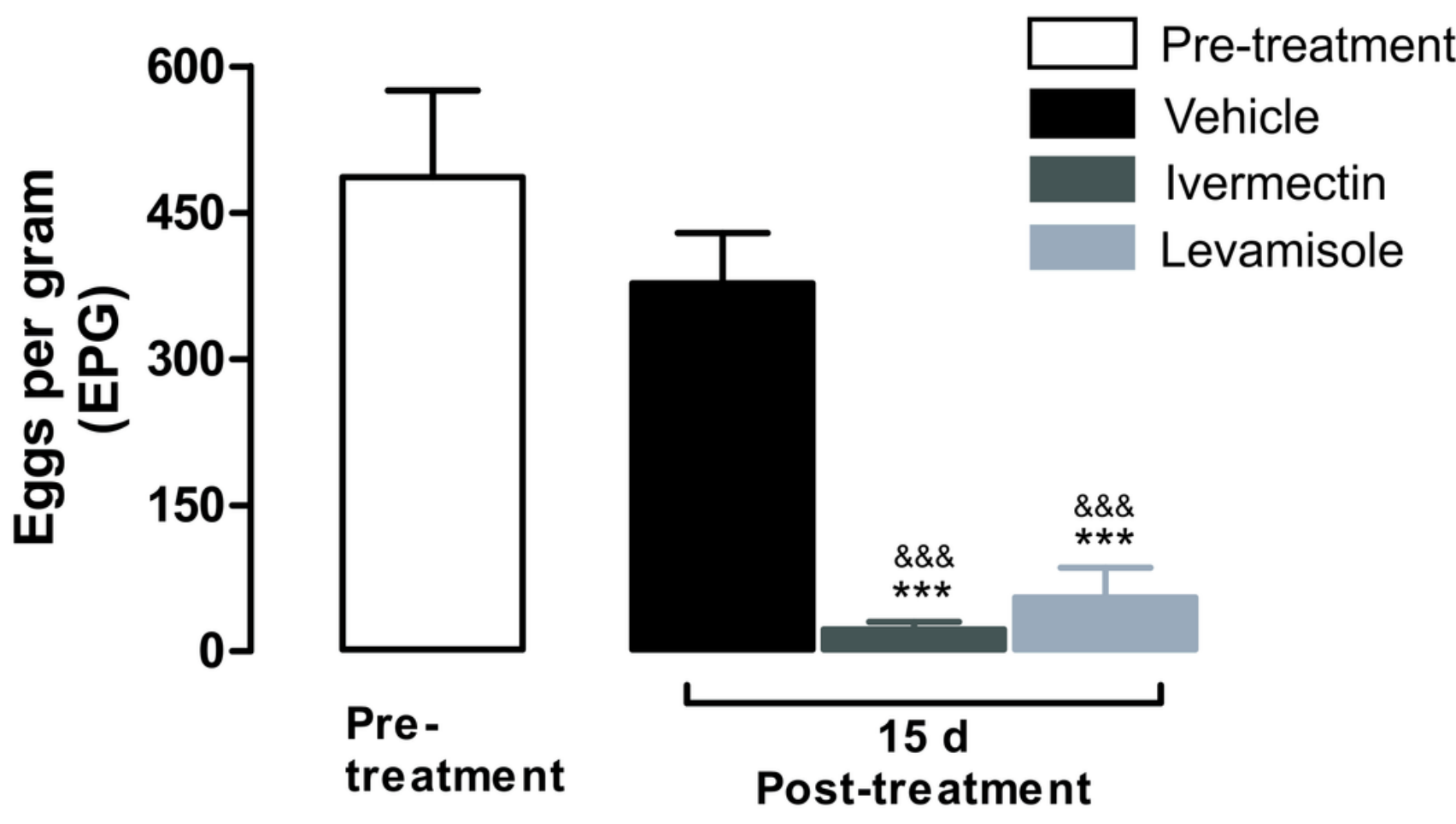

Figure 3

The levamisole and ivermectin administration decreases the eggs per gram of feces 15 days' posttreatment. It is show reduction of the EPG regarding to Pre-tratment (all groups) and vehicle group. The values show mean \pm SEM, with a Kruskal-Wallis test, followed a Dunns post hoc analysis: ${ }^{\star \star \star} p<0.001$ vs vehicle group; $++p<0.01$ vs ivermectin group. ( $n=20$ bovines per group). 